\title{
Avaliação da Função Glomerular Renal e Ventilação Pulmonar em Coelhos Submetidos ao Pneumoperitônio com Dióxido de Carbono
}

\section{Belisa Brunow Ventura Biavatti, Márcio Lopes Miranda}

\begin{abstract}
Resumo
Embora seja usual a realização de cirurgias vídeo-laparoscópicas, a ocorrência de lesões renais decorrentes destes procedimentos ainda não foi precisamente documentada na literatura médica. Todavia, é sabido que a elevação da pressão intra-abdominal por meio do pneumoperitônio cirúrgico pode ocasionar oligúria ou anúria em mamíferos. O objetivo deste trabalho é avaliar o impacto do pneumoperitônio na função glomerular renal, ventilação pulmonar e estresse oxidativo em um modelo experimental de coelhos machos, através da perfusão renal com 99mTc-DTPA (diethylene triamine pentaacetic acid, marcado com tecnécio), análise de volumes e gases respiratórios, bem como o status inflamatório e estresse oxidativo resultantes, através de marcadores específicos. Serão utilizados cinco coelhos machos Nova Zelândia saudáveis, previamente anestesiados e ventilados mecanicamente.
\end{abstract}

\section{Palavras-chave:}

Pneumoperitônio, função glomerular, DTPA.

\section{Introdução}

A realização de procedimentos exploratórios, diagnósticos e cirúrgicos através de laparoscopia data de mais de 100 anos atrás. O caráter minimamente invasivo da vídeolaparoscopia - na qual se inserem trocartes em incisões milimétricas, contendo fibra ótica, instrumentos cirúrgicos e gás para insuflação da cavidade - propicia diversos benefícios em relação às cirurgias tradicionais. $A$ insuflação com $\mathrm{CO}_{2}$, contudo, provoca alterações fisiológicas cardíacas, pulmonares e renais. A utilização da via laparoscópica para cirurgias complexas com tempo cirúrgico prolongado tem se tornado comum, de maneira que se faz necessário determinar precisamente os impactos do pneumoperitônio de $\mathrm{CO}_{2}$ nas funções fisiológicas de mamíferos, permitindo a redução de riscos e maximização das vantagens do acesso laparoscópico. Neste trabalho nos propomos a avaliar, em 5 coelhos machos saudáveis, possíveis alterações de filtração e função glomerular renal através de cintilografia, assim como alterações de marcadores inflamatórios e estresse oxidativo no sangue, e também alterações na mecânica respiratória e ventilação pulmonar através do monitoramento respiratório.

\section{Resultados e Discussão}

$O$ estudo se deu de tal maneira que cada animal foi seu próprio controle e sua função renal analisada em três momentos diferentes: perfusão de 99mTc-DTPA sem pneumoperitônio (controle - T0), com pneumoperitônio (T1) e sem pneumoperitônio (T2), sendo que os animais permaneceram durante todo 0 estudo sob monitoramento respiratório por capnografia volumétrica e foram realizadas gasometrias em cada etapa do experimento, com sacrifício ao final do procedimento.

As imagens obtidas antes, durante e depois da realização do pneumoperitônio com $\mathrm{CO}_{2}$ permitiu observar em T0 (controle) uma captação e depuração homogênea de $99 \mathrm{mTC}$-DTPA por ambos os rins e bexiga, configurando um padrão fisiológico da filtração renal.

Em T1 (com pneumoperitônio) percebe-se uma maior concentração isolada do radiofármaco em ambos os rins, implicando em dificuldade na sua eliminação, não havendo impregnação na bexiga.

Por fim, no momento T2, após desinsuflar a cavidade abdominal, observa-se um comportamento mais homogêneo e semelhante ao momento T0 (Fig. 1).

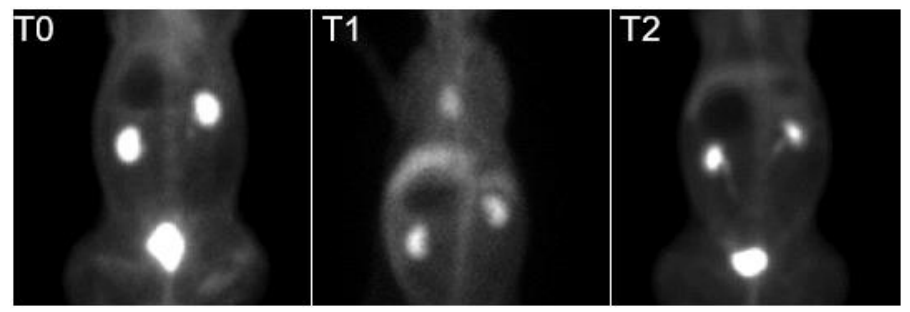

Figura 1. Captação do 99mTc-DTPA no controle (T0), durante pneumoperitônio (T1) e após desinsuflação (T3), respectivamente.

\section{Conclusões}

A análise qualitativa das imagens cintilográficas com 99mTc-DTPA evidenciou um padrão sugestivo de influência do pneumoperitônio na filtração glomerular. No modelo adotado para o experimento, o padrão de captação e depuração em T2 semelhante a T0 indica um caráter transitório da alteração, provavelmente sem lesões ou repercussões permanentes para o sistema renal dos coelhos estudados. A análise preliminar dos parâmetros respiratórios e metabólicos sugere ainda outras alterações fisiológicas durante o procedimento, a serem observadas e comparadas na próxima fase do estudo, na qual consta o processamento dos dados referentes às gasometrias e capnografias volumétricas realizadas durante o experimento.

\section{Agradecimentos}

Ao programa PIBIC pela concessão da bolsa de Iniciação Científica e à Universidade Estadual de Campinas e à Faculdade de Ciências Médicas pelo apoio estrutural. 